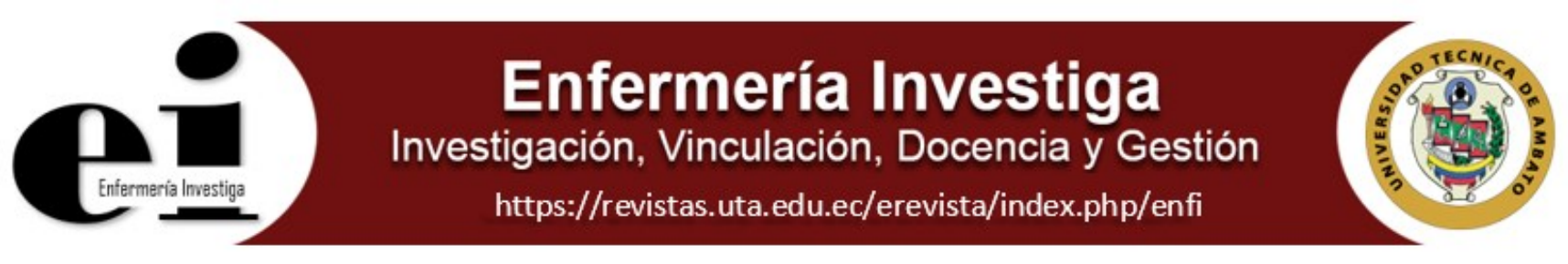

Artículo original

\title{
Concentraciones Séricas de la Enzima Acetilcolinesterasa en Agricultores Expuestos a Organofosforados.
}

Serum Concentrations of the Acetylcholinesterase Enzyme in Farmers Exposed to Organophosphates.

Anchatipán-Escobar Juan ${ }^{3}$ 0000-0003-1425-9331, Vailati Juan Pablo² 0000-0002-5380-194X, Viteri-Robayo Carmen $^{3}$ 0000-0003-2780-8790

1Universidad Técnica de Ambato; ${ }^{2}$ Carrera de Laboratorio Clínico, Universidad Técnica de Ambato; ${ }^{3}$ Carrera de Nutrición, Universidad Técnica de Ambato.

Anchatipán-Escobar, J; Vailati, J; Viteri-Robayo, C. Concentraciones Séricas de la Enzima Acetilcolinesterasa en Agricultores Expuestos a Organofosforados. Enferm Inv. 2020;5(3):39-45

2477-9172 / 2550-6692 Derechos Reservados @ 2020 Universidad Técnica de Ambato, Carrera de Enfermería. Este es un artículo de acceso abierto distribuido bajo los términos de la Licencia Creative Commons, que permite uso ilimitado, distribución y reproducción en cualquier medio, siempre que la obra original es debidamente citada.

\section{Historia:}

Recibido: 01 abril 2020

Aceptado: 20 junio 2020

Palabras Claves: Plaguicidas, organofosforados, intoxicación colinestersa.

Keywords: Pesticides, organophosphates, poisoning, cholinesterase

\begin{abstract}
Resumen
Introducción: los casos de intoxicación por plaguicidas son una causa importante de morbilidad y mortalidad a nivel mundial, cada año 3 millones de personas se envenenan por plaguicidas, en Ecuador, en el 2011, el 49,2 \% del total de intoxicados fue por plaguicidas. El objetivo: determinar las concentraciones séricas de la acetílcolisterasa y perfil hepático en de agricultores expuestos a organofosforados del Cantón Píllaro. Método: se trata de un estudio no experimental, en el que se determinó la concentración sérica de la enzima acetilcolinesterasa en 40 agricultores, expuestos a organofosforado; así como la determinación de alteraciones en su función hepática, mediante la medición de la concentración de las enzimas TGO, TGP, bilirrubina y fosfatasa alcalina. Conclusiones: Se observa intoxicación aguda en el $17,5 \%$ de la población, con respecto a la hepatotoxicidad no se evidenció ninguna alteración en la función hepática, ya que los niveles de las enzima hepática (TGO y TGP) se encontraron dentro de los rangos normales, con respecto al tiempo de exposición se pudo observar que los 7 agricultores afectados, presentaron un tiempo de exposición entre 11 a 30 años, así mismo se evidenció que los más afectados eran aquellos que no utilizaron ningún equipo de protección
\end{abstract}

\begin{abstract}
Introduction: cases of pesticide poisoning are an important cause of morbidity and mortality worldwide, every year 3 million people are poisoned by pesticides, in Ecuador, in 2011, $49.2 \%$ of the total poisoned was by pesticides. Objective: to determine the serum complications of acetylcholisterase and liver profile in farmers affected by organophosphates in the Pillaro canton. Method: it is a nonexperimental study, in which the serum concentration of the enzyme acetylcholinesterase was determined in 40 farms, an organophosphate was reduced; as well as the determination of alterations in their liver function, by measuring the concentration of GOT/GPT, bilirubin and alkaline phosphatase enzymes. Conclusions: If you observe acute intoxication in $17.5 \%$ of the population, with respect to hepatotoxicity, no alteration in liver function is evident, since liver enzyme levels (GOT/GPT) are within the ranges normal, with respect to the time of exposure it was observed that the 7 affected farmers, the exposure to an exposure time between 11 to 30 years, as well as evidence of the most affected were those who did not use any protective equipment
\end{abstract}

Autor de correspondencia: Vailati Juan Pablo. Carrera de Laboratorio Clínico, Universidad Técnica de Ambato. E-mail: jp.vailati@uta.edu.ec 


\section{Introducción}

El Manual de normas de bioseguridad para la red de En la actualidad los casos de intoxicación aguda por plaguicidas (IAP) son una causa importante de morbilidad y mortalidad a nivel mundial. De acuerdo con la Organización Mundial de la Salud, cada año terminan envenenadas por plaguicidas 3 millones de personas, la mayoría en los países en desarrollo, de las cuales mueren unas 20.000 personas, pues en ellos coinciden no solo una escasa regulación de los productos químicos agrícolas, sino también una falta de sistemas de vigilancia, un menor cumplimiento de las normas de bioseguridad y un acceso insuficiente a los sistemas de información. Investigaciones anteriores han puesto de relieve una gran variabilidad de las tasas de incidencia de IAP. Ello se debe posiblemente a unos métodos de notificación incongruentes y a la exclusión de las intoxicaciones laborales y no intencionales (1).

Según las estimaciones de la Oficina Internacional del Trabajo (OIT), un mínimo de 170.000 trabajadores agrícolas muere cada año, siendo víctimas de lesiones graves causadas por accidentes con maquinaria o por envenenamiento con pesticidas $u$ otros agroquímicos (2).

En un informe elaborado en el 2012 por el Centro de Información y Asesoramiento Toxicológico en Ecuador, se muestra que los plaguicidas siguen figurando entre los principales agentes causantes de intoxicaciones. En el 2011, el 49,2 \% de los 2,527 casos registrados correspondió a intoxicaciones por plaguicidas (insecticidas, fungicidas, larvicidas, nematicidas). El almacenamiento inadecuado o la aplicación incorrecta detonan el problema. Las personas no reciben el adecuado asesoramiento tanto para su uso, como para su correcto almacenamiento, lo que incrementa el riesgo de alteraciones en su estado de salud tanto a corto, mediano y a largo plazo (3).

Actualmente, más de 40 plaguicidas organofosforados están registrados para su uso, todos con el riesgo de causar tanto intoxicaciones agudas, como alteraciones crónicas en el estado de salud de las personas ya sea de tipo neurodegenerativas, respiratorias, reproductivas, del desarrollo y metabólicas $(4,5)$.

Los compuestos organofosforados son ésteres del ácido fosfórico y de sus derivados, que se caracterizan por ser liposolubles y volátiles, lo que facilitan su absorción; sus efectos farmacológicos varían de acuerdo con el grado de toxicidad y vía de entrada en el organismo (6). Estas sustancias pueden penetrar al organismo por inhalación, ingestión y a través de la piel intacta, debido a su alta liposolubilidad. Una vez absorbidos y distribuidos en el organismo poseen una vida media corta en el plasma y un elevado volumen de distribución en los tejidos, estos plaguicidas son metabolizados principalmente en el hígado y eliminados por el riñón (7). Su toxicidad se produce a través de la fosforilación de la enzima acetilcolinesterasa en las terminaciones nerviosas. Los pesticidas organofosforados reaccionan con la zona esterásica de la enzima colinesterasa formando una unión estable y quedando la enzima inhabilitada para su función normal. La pérdida de la función enzimática permite la acumulación de acetilcolina en las uniones colinérgicas neuroefectoras (efectos muscarínicos), en las uniones mioneurales del esqueleto y los ganglios autónomos (efectos nicotínicos) y en el sistema nervioso central (SNC) $(8,9)$.

La acetilcolina en un neurotransmisor que interactúa con los receptores postsinápticos (nicotínicos y muscarínicos), siendo responsable de la transmisión fisiológica del impulso nervioso de las fibras colinérgicas postganglionares simpáticas y parasimpáticas (receptores muscarínicos), además de las neuronas preganglionares a las postganglionares en los sistemas simpático y parasimpático (receptores muscarínicos), y por último de los nervios motores del musculo esquelético (receptores nicotínicos), y de algunas terminaciones nerviosas en el sistema nervioso central. Una vez liberada la acetilcolina, esta interactúa con su receptor, y posteriormente es hidrolizada por la colinesterasa, produciendo así colina y ácido acético, que entran al pool metabólico presináptico para ser utilizado nuevamente (10).

Las manifestaciones de intoxicación por compuestos organofosforados pueden presentarse de tres formas diferentes: como intoxicaciones agudas, también conocido como síndrome colinérgico el cual se presenta como consecuencia de la excesiva estimulación de los receptores de acetilcolina, y se caracteriza principalmente por cambios en el estado de conciencia, debilidad muscular y excesiva actividad secretora; el síndrome intermedio, el cual parece posterior a 24 - 48 horas de la exposición y se caracteriza por debilidad de los músculos proximales de las extremidades, flexores del cuello, lengua, faringe y músculos respiratorios, disminución o ausencia de los reflejos miotendinosos y compromiso de pares los craneales (principalmente el sexto); la neuropatía retardada, la cual se presenta principalmente con los compuestos que contienen flúor, puede iniciarse entre una a cuatro semanas después de la exposición aguda al tóxico, se manifiesta con debilidad ascendente pero de predominio distal, ataxia, hipotrofia muscular, hiporreflexia en miembros inferiores, calambres, parestesias, dolor neuropático, e hipoestesia $(10,11)$. Estos trastornos neurológicos van a tener una mayor incidencia en aquellas personas que mantienen un contacto directo y prolongado con dichos compuestos organofosforados (12).

De igual manera se ha asociado la exposición ocupacional a plaguicidas organofosforados a la presencia de alteraciones en la función respiratoria, manifestada principalmente por sibilantes, tos seca, disnea y patrones en la espirometría de tipo obstructivo, cuya relación causal, sigue siendo motivo de estudio (13).

Se ha encontrado evidencia sobre la relación existente entre una exposición crónica a organofosforados y la aparición de síntomas extrapiramidales y psiquiátricos como psicosis, ansiedad, depresión, alucinaciones y agresividad; así como también alteraciones de tipo 
cognitivas como es el caso de dificultades en las funciones ejecutivas, disminución de la velocidad psicomotora, verbal, memoria, coordinación y velocidad de procesamiento $(14,15)$.

El mayor riesgo de exposición que pueden presentar los agricultores, se centra principalmente, en la acumulación de los plaguicidas organofosforados en la piel, la ropa y las botas de los trabajadores; así como la exposición por inhalación, durante la aplicación de estos compuestos (16).

En un estudio realizado en la población de la Cuca, en el Cantón Arenilla, de la Provincia del Oro, se pudo demostrar que la población expuesta a plaguicida tipo organofosforado, presentaron niveles de la enzima colinesterasa por debajo de los valores normales, concluyendo, que la inhalación de compuestos organofosforados en un tiempo prolongado afecta gravemente a la salud de las personas expuestas (17).

Un estudio realizado a pequeños agricultores de la zona rural de Tanzania, reveló que las personas expuestas laboralmente a los pesticidas organofosforados, presentaban niveles significativamente más bajos de la enzima acetilcolinesterasa, que aquellos no expuestos. Igualmente evidenció una mayor prevalencia de síntomas como: cansancio, fatiga, dolor en las articulaciones, irritación de la piel, dolor abdominal, debilidad muscular y pérdida de memoria, entre las personas expuesto a los pesticidas (18).

Guanochanga realizó un estudio sobre la determinación de la concentración sérica de la pseudocolinesterasa y sus consecuencias en la función hepática en trabajadores de una empresa florícola expuestos directa e indirectamente a plaguicidas organofosforados. La muestra está conformada por 109 personas entre hombres y mujeres, a los cuales se les cuantificó los niveles séricos de la pseudocolinesterasa y se les midió el perfil hepático, mediante el método cinético espectrofotométrico. Se evidenció dentro de los resultados, una disminución en la concentración sérica de la pseudocolinesterasa en 11 trabajadores que representó el $10.1 \%$ de la población estudiada, de los cuales se pudo observar valores relativamente altos de la concentración de las enzimas hepáticas: TGO en el $45.5 \%$ (5 trabajadores), TGP en el $36.4 \%$ (4 personas) y fosfatasa alcalina en el 27.3\% (3 trabajadores)(19).

A demás se han realizado diversos estudios que han abordado la influencia de la exposición a plaguicidas sobre el perfil hematológico, encontrando alteraciones del hemograma. Con respecto al perfil bioquímico, se han estudiado especialmente las pruebas de función hepática tales como las transaminasas (AST y ALT), así como también su efecto sobre las diversas esterasas $(21,22)$.

La medición de los biomarcadores para la depresión de la colinesterasa, tienen la ventaja adicional de reflejar la reacción biológica de los plaguicidas mucho antes de que produzcan efectos adversos sobre la salud, así como también permiten una mejor evaluación del estado de gravedad de la intoxicación y la efectividad de las terapias suministradas $(22,23)$. Por esta razón se planteó como objetivo de esta investigación, determinar las concentraciones séricas de la acetílcolisterasa y perfil hepático en de agricultores expuestos a organofosforados del cantón Píllaro.

\section{Materiales y métodos}

Se realizó un estudio de tipo no experimental, cuantitativo, descriptivo y transversal, en el que se determinó la concentración sérica de la enzima acetilcolinesterasa en un grupo de agricultores, que han estado expuestos a los plaguicidas tipo organofosforado; así como la determinación de alteraciones en su función hepática, mediante la medición de la concentración sérica de la transaminasa glutámico-oxalacética (TGO), transaminasa glutámicopirúvica (TGP), bilirrubina total y directa y fosfatasa alcalina.

La muestra objeto de estudio se seleccionó a través de una técnica de muestreo no-probabilístico, por cuotas, seleccionando a 40 agricultores: 20 hombres y 20 mujeres, los cuales cumplen con los siguientes criterios:

\section{Criterios de inclusión}

- Pobladores del cantón Pillaro cuya actividad económica sea la agricultura.

- Agricultores expuestos a plaguicidas tipo organofosforados.

Agricultores expuestos a plaguicidas tipo organofosforados en edades comprendidas entre 20 y 65 años.

- $\quad$ Agricultores expuestos a organofosforados por 5 años o más.

\section{Criterios de exclusión}

- Agricultores expuestos a plaguicidas tipo organofosforados con antecedentes de hepatopatías previa.

- Agricultores expuestos a plaguicidas tipo organofosforados con antecedentes de anemia.

La información demográfica fue obtenido a través de una encuesta ocupacional realizada a cada uno de los agricultores estudiados, en donde se recolectaron los datos referentes a la edad, sexo, tiempo de exposición a los plaguicidas organofosforados, así como el uso o no de equipos de bioseguridad durante su utilización.

Se obtuvo la muestra de sangre venosa periférica mediante técnica de venopunción con vacutainer, siguiendo los protocolos de bioseguridad. Las muestras son trasladadas al laboratorio en una caja térmica con gel refrigerante a una temperatura promedio de $6^{\circ} \mathrm{C}$, para posteriormente se centrifugada y procesada dentro de las siguientes 2 horas. La determinación de la acetilcolinesterasa y de la fosfatasa alcalina se realizó utilizando el método cinético espectrofotométrico (Wiener-lab), mientras que la determinación de la TGO y TGP se realizó utilizando el método cinético 
espectrofotométrico (liquiUV). Se reportó cada uno de los resultados en la hoja de registro para ser analizada.

Las variables estudiadas en esta investigación, consisten en los cambios en la concentración sérica de la acetilcolinesterasa y de las enzimas hepáticas en relación con la edad y sexo de los agricultores estudiados; así como el tiempo de exposición al plaguicida tipo organofosforado, clasificándolos como: de baja exposición, a aquellos agricultores expuestos entre 5 a 10 años, de mediana exposición, a los agricultores expuestos entre 11 a 30 años, y de alta exposición a los agricultores expuestos durante más de 31 años; y el uso o no de equipo de bioseguridad, durante su utilización.

Los resultados obtenidos fueron organizados en tablas y gráficos de frecuencia y porcentuales, realizando su validación estadística mediante el uso de la T student y del Chi cuadrado, con una $p<0,05$ para el significado estadístico

\section{Aspectos éticos}

El presente proyecto de investigación, se usó el principio de autonomía informado a cada uno de los pacientes, informándolos de los pormenores de los exámenes que se los va a realizar, tomando en cuenta que el paciente tiene la libertad y responsabilidad de decidir que es bueno para su integridad, sin influencias ni presiones externas, respetando así sus derechos humanos.

Respetando los derechos humanos, para la realización de este proyecto investigativo, se aplicó una carta de consentimiento informado, solicitando la aprobación de cada uno de los pacientes para la extracción y ejecución de sus fluidos biológicos.

\section{Resultados}

Mediante el análisis del nivel de conocimientos de los Fueron evaluados, un total de 40 personas, cuya actividad económica es la agricultura en el cantón Píllaro, durante 5 años o más y que utilizan plaguicidas tipo organofosforados, en sus plantaciones. Los cuales se encuentran conformados por: un $50 \%(n=20)$ hombre y $50 \%(n=20)$ mujeres, en edades comprendidas entre: $25-35$ años un $30 \%(n=12), 36-45$ años un $30 \%(n=12)$, 46-55 años un 27,5\% $(n=11), 56-65$ años un $7,5 \%(n=3)$, $66-75$ años un $2,5 \%(n=1)$ y $76-85$ años un $2,5 \%(n=1)$, de la población estudiada.

Tabla $\mathbf{N}^{\circ} \mathbf{1}$. Nivel de concentración de acetilcolinesterasa en agricultores expuestos a organofosforados.

\begin{tabular}{|c|c|c|}
\hline $\begin{array}{l}\text { Nivel de concentración de } \\
\text { acetilcolinesterasa }\end{array}$ & Frecuencia & Porcentaje \\
\hline $3140-6100 \mathrm{U} / \mathrm{I}$ & 33 & $82,50 \%$ \\
\hline & 7 & $17,50 \%$ \\
\hline Total & 40 & $100,00 \%$ \\
\hline
\end{tabular}

En relación con la concentración sérica de la acetilcolinesterasa, se pudo observar, que el $82,5 \%$ $(n=33)$ presentaron niveles de acetilcolinesterasa, dentro de los rangos normales, sin embargo, el $17,5 \%$ $(n=7)$, presentó una disminución en la concentración de esta enzima (tabla $\mathrm{N}^{\circ} 1$ ), lo cual no es estadísticamente significativo, de acuerdo con la T-Student cuyo valor es de 3,636.

Tabla N². Determinación de perfil hepático: TGO, TGP, bilirrubina directa, indirecta y fosfatasa alcalina de los agricultores expuestos a plaguicidas organofosforados.

\begin{tabular}{|c|c|c|c|}
\hline Perfil hepático & & Frecuencia & Porcentaje \\
\hline \multirow[t]{6}{*}{ TGO } & Hombres & 20 & 50,00 \\
\hline & $<37 \mathrm{U} / \mathrm{l}$ & 0 & 0 \\
\hline & $>37 \mathrm{U} / \mathrm{I}$ & & \\
\hline & Mujeres & 20 & 50,00 \\
\hline & $<31 \mathrm{U} / \mathrm{l}$ & 0 & 0 \\
\hline & $>31 \mathrm{U} / \mathrm{l}$ & & \\
\hline \multirow[t]{6}{*}{ TGP } & Hombres & 20 & 50,00 \\
\hline & $<42 \mathrm{U} / \mathrm{l}$ & 0 & 0 \\
\hline & $>42 \mathrm{U} / \mathrm{l}$ & & \\
\hline & Mujeres & 20 & 50,00 \\
\hline & $<32 \mathrm{U} / \mathrm{I}$ & 0 & 0 \\
\hline & $>32 \mathrm{U} / \mathrm{l}$ & & \\
\hline \multirow{2}{*}{$\begin{array}{l}\text { Bilirrubina } \\
\text { Directa }\end{array}$} & $\begin{array}{l}<0,25 \\
\mathrm{ma} / \mathrm{dl}\end{array}$ & 40 & 100,00 \\
\hline & $\begin{array}{l}>, 25 \\
\mathrm{mg} / \mathrm{dl}\end{array}$ & 0 & \\
\hline \multirow[t]{2}{*}{ Bilirrubina Total } & $<1,1 \mathrm{mg} / \mathrm{dl}$ & 40 & 100,00 \\
\hline & $>1,1 \mathrm{mg} / \mathrm{dl}$ & 0 & \\
\hline \multirow[t]{2}{*}{$\begin{array}{l}\text { Fosfatasa } \\
\text { Alcalina }\end{array}$} & $\begin{array}{l}80-306 \\
u / l\end{array}$ & 40 & 100,00 \\
\hline & $>306 \mathrm{u} / \mathrm{l}$ & 0 & \\
\hline
\end{tabular}

Fuente: Los Autores

Con respecto a la hepatotoxicidad, no se lograron evidenciar alteraciones en la función hepática, ya que los resultados obtenidos de las enzimas hepáticas (TGO, TGO), la bilirrubina y fosfatasa alcalina, se encontraron dentro de los rangos normales (tabla $\mathrm{N}^{\circ} 2$ ).

Tabla $\mathbf{N}^{\circ} \mathbf{3}$ Concentración de la acetilcolinesterasa, en relación con la edad de los agricultores estudiados.

\begin{tabular}{|c|c|c|c|c|}
\hline & \multicolumn{4}{|c|}{$\begin{array}{l}\text { Concentración sérica de } \\
\text { Acetilcolinesterasa }\end{array}$} \\
\hline \multirow[t]{2}{*}{ Edad (años) } & & \multicolumn{2}{|c|}{ Valor } & Total \\
\hline & & $\begin{array}{c}3140- \\
6100 \mathrm{U} / \mathrm{L}\end{array}$ & $\begin{array}{c}\text { Menor } \\
\text { a } \\
3139.9 \\
\text { U/L }\end{array}$ & \\
\hline \multirow[t]{2}{*}{$25-35$} & Recuento & 10 & 2 & 12 \\
\hline & $\%$ del total & $25,0 \%$ & $5,0 \%$ & $30,0 \%$ \\
\hline \multirow[t]{2}{*}{$36-45$} & Recuento & 8 & 4 & 12 \\
\hline & $\%$ del total & $20,0 \%$ & $10,0 \%$ & $30,0 \%$ \\
\hline $46-55$ & Recuento & 10 & 1 & 11 \\
\hline
\end{tabular}




\begin{tabular}{|c|c|c|c|c|c|}
\hline & & $\%$ del total & $25,0 \%$ & $2,5 \%$ & $27,5 \%$ \\
\hline \multirow{2}{*}{\multicolumn{2}{|c|}{$56-65$}} & Recuento & 3 & 0 & 3 \\
\hline & & $\%$ del total & $7,5 \%$ & $0,0 \%$ & $7,5 \%$ \\
\hline \multirow{2}{*}{\multicolumn{2}{|c|}{$66-75$}} & Recuento & 1 & 0 & 1 \\
\hline & & $\%$ del total & $2,5 \%$ & $0,0 \%$ & $2,5 \%$ \\
\hline \multirow{2}{*}{\multicolumn{2}{|c|}{$76-85$}} & Recuento & 1 & 0 & 1 \\
\hline & & $\%$ del total & $2,5 \%$ & $0,0 \%$ & $2,5 \%$ \\
\hline \multirow{2}{*}{\multicolumn{2}{|c|}{ Total }} & Recuento & 33 & 7 & 40 \\
\hline & & $\%$ del total & $82,5 \%$ & $17,5 \%$ & $\begin{array}{c}100,0 \\
\%\end{array}$ \\
\hline
\end{tabular}

En referencia a la disminución en la concentración de la acetilcolinesterasa, de acuerdo al grupo etario, se pudo constatar que un $5 \%(n=2)$ de los afectados presentan edades comprendidas entre $25-35$ años, un $10 \%(n=4)$ presentan edades comprendidas entre $36-45$ años y un $2,5 \%(n=1)$ presentan edades comprendidas entre $46-55$ años (tabla $\mathrm{N}^{\circ} 3$ ), lo cual no resulta estadísticamente significativo con una $p>0.05$.

Tabla $\mathbf{N}^{\circledR} \mathbf{4}$ Concentración de la acetilcolinesterasa, en relación con el género de los agricultores estudiados.

\begin{tabular}{clccc}
\hline Concentración de acetilcolinesterasa \\
\cline { 3 - 4 } & & \multicolumn{2}{c}{ Sexo } & Total \\
\cline { 2 - 4 } & & Femenino & Masculino & \\
\hline $\begin{array}{c}3140- \\
6100 \mathrm{U} / \mathrm{l}\end{array}$ & Recuento & 16 & 17 & 33 \\
\cline { 2 - 4 } & $\%$ del & $40,0 \%$ & $42,5 \%$ & $82,5 \%$ \\
& total & & & \\
\hline MENOR & Recuento & 4 & 3 & 7 \\
$\begin{array}{c}\text { 3139.9 } \\
\text { U/l }\end{array}$ & $\begin{array}{l}\% \text { del } \\
\text { total }\end{array}$ & $10,0 \%$ & $7,5 \%$ & $17,5 \%$ \\
\hline Total & Recuento & 20 & 20 & 40 \\
\cline { 2 - 4 } & $\%$ del & $50,0 \%$ & $50,0 \%$ & $100,0 \%$ \\
& total & & \\
\hline
\end{tabular}

Fuente: Los Autores

Referente a la disminución de la enzima acetilcolinesterasa, con respecto al sexo de los agricultores estudiados, podemos observar, que el $10 \%$ $(n=4)$ son de sexo femenino y el $7,5 \%(n=3)$ son de sexo masculino (tabla $\mathrm{N}^{\circ} 4$ ), lo cual no resulta estadísticamente significativo, con una $p>0.05$.

Tabla $\mathbf{N}^{\circ} \mathbf{5}$ Concentración sérica de acetilcolinesterasa en relación con el tiempo de exposición.

\begin{tabular}{|c|c|c|c|c|}
\hline \multirow[t]{2}{*}{$\begin{array}{l}\text { Tiempo de } \\
\text { exposición. }\end{array}$} & \multicolumn{2}{|c|}{$\begin{array}{l}\text { Concentración } \\
\text { acetilcolinesterasa } \\
\qquad 3140-6100 \mathrm{U} / \mathrm{L}\end{array}$} & \multirow[t]{2}{*}{ sérica } & de \\
\hline & & & & $\begin{array}{c}\text { Menor a } \\
3139.9 \\
\text { U/L }\end{array}$ \\
\hline \multirow[t]{5}{*}{ Exposición: } & \multirow[t]{2}{*}{ Baja } & Recuento & 9 & 0 \\
\hline & & $\begin{array}{l}\% \text { dentro } \\
\text { de } \\
\text { expuestos }\end{array}$ & $22,5 \%$ & $0,0 \%$ \\
\hline & \multirow[t]{2}{*}{ Mediana* } & Recuento & 19 & 7 \\
\hline & & $\begin{array}{l}\text { \% dentro } \\
\text { de } \\
\text { expuestos }\end{array}$ & $47,5 \%$ & $17,5 \%$ \\
\hline & Alta & Recuento & 5 & 0 \\
\hline
\end{tabular}

\begin{tabular}{llcc}
\hline & $\begin{array}{l}\% \text { dentro } \\
\text { de }\end{array}$ & $12,5 \%$ & $0,0 \%$ \\
expuestos & & \\
\hline Total & $\begin{array}{l}\text { Recuento } \\
\text { Rec }\end{array}$ & 33 & 7 \\
\cline { 2 - 4 } $\begin{array}{l}\% \text { dentro } \\
\text { de } \\
\text { expuestos }\end{array}$ & $82,5 \%$ & $17,5 \%$ \\
\hline
\end{tabular}

Fuente: Los Autores, ${ }^{*} p<0,05$ para el significado estadístico

Con respecto al tiempo de exposición a plaguicida organofosforado, se definió como de baja exposición, aquello agricultores expuestos durante 5 a 10 años, de mediana exposición aquellos agricultores expuestos entre 11 a 30 años, y de alta exposición aquellos agricultores con más de 31 años de exposición. Evidenciando que el 17,5\% ( $n=7)$ de la población estudiada (tabla $\mathrm{N}^{\circ} 5$ ), presentaron una disminución de la enzima acetilcolinesterasa, los cuales presentaban una mediana exposición a este organofosforado, lo cual es estadísticamente significativo con una $p<0,05$.

Tabla $\mathbf{N}^{\circ} \mathbf{6}$ Concentración de acetilcolinesterasa en agricultores expuestos a plaguicidas organofosforados en relación con el uso o no de medidas de bioseguridad.

\begin{tabular}{|c|c|c|c|c|c|}
\hline \multicolumn{6}{|c|}{ Concentración sérica de acetilcolinesterasa } \\
\hline & & & \multirow{2}{*}{\multicolumn{2}{|c|}{ Valor. }} & Total \\
\hline & & & & & \\
\hline & & & $\begin{array}{c}3140- \\
6100 \\
\text { U/L }\end{array}$ & $\begin{array}{l}\text { Menor } \\
\text { a } \\
3139.9 \\
\text { U/L }\end{array}$ & \\
\hline \multirow{4}{*}{$\begin{array}{l}\text { Uso de } \\
\text { bioseguridad }\end{array}$} & \multirow[t]{2}{*}{ No } & Recuento & 0 & $7^{*}$ & 7 \\
\hline & & $\begin{array}{l}\text { \% dentro } \\
\text { de la } \\
\text { población }\end{array}$ & 0 & $17,5 \%$ & $17,5 \%$ \\
\hline & \multirow[t]{2}{*}{$\mathrm{Si}$} & Recuento & 33 & 0 & 33 \\
\hline & & $\begin{array}{l}\% \text { dentro } \\
\text { de la } \\
\text { población }\end{array}$ & $82,5 \%$ & 0 & $82,5 \%$ \\
\hline \multirow[t]{2}{*}{ Total } & & Recuento & 33 & 7 & 40 \\
\hline & & $\begin{array}{l}\text { \% dentro } \\
\text { de la } \\
\text { población }\end{array}$ & $82,5 \%$ & $17,5 \%$ & $100,0 \%$ \\
\hline
\end{tabular}

Con respecto al uso de equipos de bioseguridad como guantes o lentes de protección, durante la manipulación de los plaguicidas organofosforados, se pudo constatar que el $17,5 \%(n=7)$, no utilizaron ningún implemento de seguridad, siendo estos los que presentaron valores de acetilcolinesterasa menor a $3139.9 \mathrm{U} / \mathrm{L}$ (tabla $\mathrm{N}^{\circ} 6$ ), lo cual es estadísticamente significativo $p<0,05$.

\section{Discusión}

La exposición a plaguicidas tipo organofosforados puede afectar el estado de salud de las personas expuestas directamente a este, evidenciado mediante la disminución de la enzima acetilcolinesterasa, lo cual se pudo observar en el $17,5 \%$ de la población objeto de estudio, lo que coincide con el estudio realizado en Quito por Martha Guanochanga (19), en una empresa, en donde se evidenció que el $10,1 \%$ de trabajadores expuestos a plaguicidas de tipo organofosforados presentaron niveles relativamente bajos de acetilcolinesterasa.(19) De igual manera un estudio realizado en la ciudad de Loja por Pizarro Silvana (2014) 
en agricultores expuestos a organofosforados, en donde de una muestras conformada por 63 agricultores, se encontró que 10 de ellos presentaron niveles de acetilcolinesterasa disminuida.(24) Así mismo un estudio realizado por Marrero, S. en el año 2017, en el que se estudió a un total de 30 individuos adultos, aparentemente sanos, divididos en dos grupos, uno expuesto (GE) conformado por trabajadores agrícolas, los cuales están expuestos a plaguicidas organofosforados; y un grupo control sin antecedentes de exposición a plaguicidas; en dicho estudio se evidenció que a pesar de que los valores promedios de la colinesterasa en ambos grupos se ubicaron dentro de los parámetros normales, un $11,7 \%$ de los valores de colinesterasa obtenidos en el grupo expuesto se ubicaron por debajo del rango de normalidad (25).

Con respecto a la hepatotoxicidad, no se evidenció ninguna alteración en la función hepática, ya que los niveles de las enzima hepática (TGO y TGP) se encontraron dentro de los rangos normales, a diferencia de estudios realizados por María Iza (2016), donde, si se evidencio un aumento significativo de las enzimas hepáticas en 7 de 44 trabajadores agrícolas expuestos a plaguicidas organofosforados(26). De igual manera un estudio realizado por Martha Guanochanga, en la ciudad de Quito (2018), pudo evidenciar que en una población de 109 personas expuestos a plaguicidas de tipo organofosforados, 11 presentaron alteraciones de las enzimas hepáticas: TGO en el $45.5 \%$ (5 trabajadores), TGP en el $36.4 \%$ (4 personas) y fosfatasa alcalina en el $27.3 \%$ (3 trabajadores), considerando que estos resultados no son estadísticamente significativos, para determinar su hepatotoxicidad.(19) Así como también podemos señalar un estudio realizado por Manyilizu, en el año 2016, donde se estudiaron 69 personas de una población agrícola expuesta a pesticidas y 30 personas de un distrito que no usan pesticidas (grupo de referencia), en este estudio se evidenció una disminución en el hematocrito y el volumen corpuscular medio, del grupo expuesto en comparación con el grupo de referencia, además se ha encontrado una deformabilidad de los eritrocitos, por lo que es probable que productos químicos como los pesticidas, puedan afectar la señalización de la acetilcolina e inducir cambios en el tamaño y volumen de los eritrocitos.(27) En comparación al estudio de Avinash, realizado en el año 2015, en los campos de cultivo de uva en la India, en donde se estudiaron a 27 fumigadores en contacto con pesticidas en el grupo de estudio y 27 no fumigadores en el grupo de control, en donde analizaron el perfil hematológico y los parámetros bioquímicos, evidenciando que a pesar que el recuento de glóbulos blancos (WBC) se redujo significativamente y el nivel de ácido úrico y malondialdehído (MDA) aumentó significativamente entre el grupo de estudio y el grupo control, no se encontró diferencias estadísticamente significativas entre ambos grupos.(28)

Con respecto al tiempo de exposición a los plaguicidas organofosforados, se pudo observar en nuestro estudio, que los 7 agricultores afectados, presentaron un tiempo de exposición entre 11 a 30 años. Al igual que en estudios realizados por María Iza (2016), en 44 pacientes donde 7 de ellos tenían disminución en la concentración de la acetilcolinesterasa y en la que concluyeron que la disminución en la concentración de la enzima se ve afectada por el tiempo de exposición y la actividad que desempeñan los floricultores (26).

En nuestro estudio logramos evidenciar que los 7 agricultores que no utilizaron ningún equipo de bioseguridad fueron los que presentaron una disminución de la concentración de acetilcolinesterasa. A diferencia de un estudio realizado por Marcela Verona, en la que se realizó un estudio transversal a 204 trabajadores ocupacionalmente expuestos a plaguicidas organofosforado, en cuatro municipios del departamento de Putumayo, según la información recolectada, 163 $(79,9 \%)$ de los trabajadores refirieron que utilizan algún elemento de protección personal cuando están aplicando los plaguicidas, evidenciando que de los elementos de protección personal reportados, se encontró una relación estadísticamente significativa entre el uso de botas de caña alta y la menor probabilidad de presentar intoxicaciones por plaguicidas (29).

Es oportuno indicar que la Office of Enviromental Health Hazard Assessment, en su quinta edición publicada en el año 2015, recomienda en los estudios de evaluación de la actividad de la colinesterasa en expuestos a plaguicidas organofosforados y carbamatos, debe realizarse a los trabajadores antes de la exposición, para establecer los niveles basales o "Línea de base", posteriormente realizar las mismas pruebas a los trabajadores que han estado expuestos a plaguicidas inhibidores de la colinesterasa por más de seis días, en un período de 30 días como parte del llamado "Seguimiento" y por último se les debe realizar evaluaciones después de que se han retirado de la exposición. Esta fase de "Recuperación" es aplicable para los que reportaron valores de colinesterasa por debajo de los rangos de referencia.(30) Sin embargo, en la población estudiada, no se pudo realizar este seguimiento porque los agricultores se encuentran expuestos a plaguicidas organofosforados todo el año, a razón de la diversidad de cultivos que manejan, sin embargo es importante resaltar con nuestra investigación, que las personas que no tienen conocimiento del uso de métodos de bioseguridad frente a este tipo de plaguicidas tienen más predisposición a presentar afectaciones en su estado de salud.

\section{Conflicto de intereses}

Ninguno declarado por los autores.

\section{Financiación}

Autofinanciado.

\section{Agradecimientos}

Ninguno declarado por los autores.

\section{Referencias}

1. Josef G Thundiyil, Judy Stober, Nida Besbelli JP. Intoxicación aguda por plaguicidas: propuesta de instrumento de clasificación. Boletin de 
la Organización Mundial de la Salud; 2008:161-240. Disponible en: http://www.who.int/bulletin/volumes/86/3/07-041814-ab/es/

2. Oficina Internacional del Trabajo. Seguridad y Salud en la Agricultura. Ginebra - Suiza: SafeWork; 2000. Disponible en: http://www.ilo.org/wcmsp5/groups/public/@ed_protect/@protrav/@saf ework/documents/publication/wcms_117460.pdf

3. Pinto W. Agricultores, en riesgo por el uso de los agroquímicos. Diario el Universo; 2015 May 10; Disponible en: https://www.eluniverso.com/noticias/2015/05/10/nota/4853501/agricul tores-riesgo-uso-agroquimicos

4. Agencia de Protección Ambiental de Estados Unidos. Insecticidas Organofosfatados. Disponible en https://espanol.epa.gov/sites/production-es/files/201509/documents/spch4.pdf

5. Mostafalou S, Abdollahi M. Pesticides: an update of human exposure and toxicity. Vol. 91, Archives of Toxicology. Springer Verlag; 2017:549-99. Disponible

https://pubmed.ncbi.nlm.nih.gov/27722929/

6. Weselak M, Arbuckle TE, Foster W. Pesticide Exposures and Developmental Outcomes: The Epidemiological Evidence. J Toxicol Environ Heal Part B; 2007;10(1-2):41-80. Disponible en: http://www.ncbi.nlm.nih.gov/pubmed/18074304

7. Lotti M. Cholinesterase inhibition: complexities in interpretation. Clin Chem; 1995;41(12 Pt 2):1814-8. Disponible en: http://www.ncbi.nlm.nih.gov/pubmed/7497638

8. Eddleston M, Phillips MR. Self poisoning with pesticides BMJ; 2004; 328(7430):42-4. Disponible en: http://www.ncbi.nlm.nih.gov/pubmed/14703547

9. Naughton SX, Terry A V. Neurotoxicity in acute and repeated organophosphate exposure. Toxicology; 2018; 408:101-12. Disponible en: https://pubmed.ncbi.nlm.nih.gov/30144465/

10. Daniel G. Fernández A. Md. Intoxicación por Organofosforados. Rev la Fac Med Univ Mil Nueva Granada; 2010;18(49):84-92. Disponible http://www.scielo.org.co/pdf/med/v18n1/v18n1a09.pdf

11. Muñoz-Quezada MT, Lucero B, Iglesias $\mathrm{V}$, Levy $\mathrm{K}$, Muñoz $M P$, Achú $E$, et al. Exposure to organophosphate (OP) pesticides and health conditions in agricultural and non-agricultural workers from Maule, Chile. Int J Environ Health Res; 2017; 27(1):82-93. Disponible en: http://www.ncbi.nlm.nih.gov/pubmed/28002976

12. Gilden RC, Huffling K, Sattler B. Pesticides and health risks. JOGNN - J Obstet Gynecol Neonatal Nurs; 2010; 39(1):103-110. Disponible

http://www.jognn.org/article/S0884217515302550/fulltext

13. Mamane A, Baldi I, Tessier JF, Raherison C, Bouvier G. Occupational exposure to pesticides and respiratory health. Vol. 24, European Respiratory Review. European Respiratory Society; 2015:306-319.

14. Salvi RM, Lara DR, Ghisolfi ES, Portela L V, Dias RD, Souza DO. Neuropsychiatric Evaluation in Subjects Chronically Exposed to Organophosphate Pesticides. Toxicol Sci; 2003; 72(2):267-271. Disponible en: http://www.ncbi.nlm.nih.gov/pubmed/12660361

15. Muñoz-Quezada MT, Lucero BA, Iglesias VP, Muñoz MP Cornejo CA, Achu E, et al. Chronic exposure to organophosphate (OP) pesticides and neuropsychological functioning in farm workers: a review. Vol. 22, International Journal of Occupational and Environmental Health. Taylor and Francis Ltd.; 2016. p. 68-79. Disponible en: /pmc/articles/PMC4894272/?report=abstract

16. Guytingco A, Thepaksorn P, Neitzel RL. Prevalence of Abnormal Serum Cholinesterase and Associated Symptoms from Pesticide Exposure among Agricultural Workers in the South of Thailand. J Agromedicine; 2018; 23(3):270-278. Disponible en https://pubmed.ncbi.nlm.nih.gov/30047860/

17. Silverio C, Ramón G, Guzmán E. Agricultores expuestos a compuestos organofosforados en el sitio La Cuca, cantón Arenillas, Provincia de El Oro. Cumbres; 2016;1(2):35-37. Disponible en:
http://investigacion.utmachala.edu.ec/revistas/index.php/Cumbres/arti cle/view/16

18. Kapeleka JA, Sauli E, Sadik O, Ndakidemi PA. Biomonitoring of Acetylcholinesterase (AChE) Activity among Smallholder Horticultural Farmers Occupationally Exposed to Mixtures of Pesticides in Tanzania. J Environ Public Health. 2019;2019.

19. Guanochanga Chicota Martha Ximena. "Determinación de la concentración sérica de la pseudocolinesterasa y consecuencias funcionales hepáticas en trabajadores de una empresa florícola expuestos directa e indirectamente a plaguicidas organofosforados período mayo 2018". Universidad Central del Ecuador; 2018. Disponible

http://www.dspace.uce.edu.ec/bitstream/25000/16714/1/T-UCE-0014CME-043.pdf

20. O G. Influencia de la exposición crónica a plaguicidas sobre diversos marcadores bioquímicos (esterasas y enzimas antioxidantes) en trabajadores de invernadero de la Costa Oriental de Andalucía. Universidad de Granada; 2005. Disponible en: http://digibug.ugr.es/bitstream/handle/10481/554/15376904.pdf;jsessi onid=E78FB6C1E329AB53AD22EA2C012DAAFE?sequence=1

21. Mangas I, Estevez J, Vilanova E, França TCC. New insights on molecular interactions of organophosphorus pesticides with esterases. Toxicology; 2017; 376:30-43. Disponible en: https://pubmed.ncbi.nlm.nih.gov/27311923/

22. Jalady AM, Dorandeu F. Interest of the cholinesterase assay during organophosphate poisonings. Ann Fr Anesth Reanim; 2013; 32(12):856-862. Disponible

https://pubmed.ncbi.nlm.nih.gov/24209986/

23. Strelitz J, Engel LS, Keifer MC. Blood acetylcholinesterase and butyrylcholinesterase as biomarkers of cholinesterase depression among pesticide handlers. Occup Environ Med; 2014; 71(12):842-847. Disponible en: https://pubmed.ncbi.nlm.nih.gov/25189163/

24. Zapata. S del RP. Determinación de colinesterasa sérica en usuarios de organofosforados en labores agrícolas, y su relación con la frecuencia de su uso en los habitantes del barrio el alumbre de la ciudad de Loja durante el periodo marzo-julio del 2014. Universidad Nacional de Loja; 2014. Disponible en: http://dspace.unl.edu.ec/jspui/bitstream/123456789/13711/1/TESIS.p df

25. Marrero S, González S, Guevara H, Eblen A. Comunidad y Salud. Comunidad y Salud; 2017; 15(1):30-41. Disponible en: http://www.scielo.org.ve/scielo.php?script=sci_arttext\&pid=S169032932017000100005

26. Belen ITM. Determinación de daño hepático mediante TGO - TGP y fosfatasa alcalina en personal expuesto a plaguicidas en una empresa florícola de mayo a junio 2016. Universidad Central del Ecuador; 2016. Disponible en: http://www.dspace.uce.edu.ec/bitstream/25000/8086/1/T-UCE-0006011.pdf

27. Manyilizu W, Mdegela R, Kazwala R, Nonga H, Muller M, Lie $\mathrm{E}$, et al. Association of Long-Term Pesticide Exposure and Biologic Parameters in Female Farm Workers in Tanzania: A Cross Sectional Study. Toxics; 2016; 4(4):25. Disponible en: http://www.ncbi.nlm.nih.gov/pubmed/29051428

28. Gaikwad AS, Karunamoorthy P, Kondhalkar SJ, Ambikapathy M, Beerappa R. Assessment of hematological, biochemical effects and genotoxicity among pesticide sprayers in grape garden. J Occup Med Toxicol; 2015;10:11. Disponible en: http://www.ncbi.nlm.nih.gov/pubmed/25759745

29. Varona M, Henao G, Lancheros A, Murcia Á, Díaz S, Morato $\mathrm{R}$, et al. Factores de exposición a plaguicidas organofosforados y carbamatos en el departamento del Putumayo, 2006. Biomédica; 2007; 27(3):400. Disponible en: http://www.revistabiomedica.org/index.php/biomedica/article/view/202

30. Oehha. Guidelines for Physicians Who Supervise Workers Exposed to Cholinesterase- Inhibiting Pesticides; 2015. Disponible en: www.mededpesticide.org

Enferm Inv. 5(3): 39-45 